\title{
Couchsurfing as a virtual hospitality network and a type of sustainable youth tourism
}

\author{
Olena Hanchuk ${ }^{1, *}$, Olga Bondarenko ${ }^{1}$, Iryna Varfolomyeyeva $^{1}$, Olena Pakhomova $^{2}$, and Tetyana Lohvynenko ${ }^{1}$
}

${ }^{1}$ Kryvyi Rih State Pedagogical University, 54 Gagarina Ave., Kryvyi Rih, 50086, Ukraine

${ }^{2}$ Oles Honchar Dnipro National University, 72 Haharina Ave., Dnipro, 49000, Ukraine

\begin{abstract}
The modern tourism diversity coursed by the emergence of its new varieties is sure to evolve with a view to the goals of sustainable future. The article is dedicated to couchsurfing, a kind of sustainable youth tourism, a global hospitality network, as an online service used for transcultural communication of tourists through the organization of various assistance during joint travel. It helps meet tourists' recreational needs and travelling at no charge. The article considers the organizational structure of couchsurfing as a network managed by regional units. The authors identify the factors that influence the development of this type of tourism (globalization of the world economy, the development of the Internet, the growth of human wellbeing, democratization of society and etc.). They offer a comprehensive classification of types of couchsurfing by several criteria (age of tourists, number of participants, purpose of the trip and direction, length of stay, intensity of tourist flow). The regional peculiarities of the couchsurfing development are identified, and the regions with high (Europe, Anglo-American, Australia and New Zealand), middle (Asia and Latin America) and low levels of its development (Africa, Oceania and Central America) are distinguished. The map material illustrating the spread of couchsurfing around the world is created.
\end{abstract}

\section{Introduction}

\subsection{The problem statement}

In an age of globalization social life undergoes significant changes: human relations become more open, interstate borders gradually disappear, and travel and tourism gain in popularity, especially among young people.

Tourism has grown rapidly over the last half-century, becoming one of the most profitable sectors of the economy. At the same time, the development and diversification of tourism must take into account the goals set out in the 2030 Agenda for Sustainable Development and the SDGs on the period up to 2030 [1] and should contribute to the achievement of all components of sustainable development and sustainable future. Today, sustainable tourism has become one of the priorities of the United Nations World Tourism Organization.

Simultaneously according to Snizhana Neklyudova and Valeriy Cabrin "changes in tourism are connected with the development of modern technologies, the Internet, transport, and on the other hand, changes in the nature of tourism and tourists behavior - have led to the emergence of new forms of tourism and ways of traveling" [2]. In search of new destinations and types of tourist recreation, young people are already actively mastering one of these forms - couchsurfing.

In general, sustainable development guidelines and sustainable development management practices are applicable to all forms and types of tourism, so couchsurfing is no exception.

\subsection{The objective of the article}

The purpose of the proposed publication is to characterize couchsurfing as a type of youth tourism and the most popular modern global hospitality network. We also briefly consider the contribution of tourism and couchsurfing as its type to the Sustainable Development Goals.

\subsection{Theoretical background}

Tourism as a subject of research has been considered in scientific works for a long time, because over the long history of the development of human travel there are peculiar forms of hospitality.

However, as noted above, in the information society, traditional varieties of hospitality are taking on new content and new forms [3]. Virtual hospitality networks have become one of these new phenomena, and couchsurfing is one of the most popular, but at the same time the least researched one.

A theoretical generalization of the scientific literature makes it possible to argue that couchsurfing (couch - a type of high bed, especially one in a doctor's office, and surfing - traveling) is a global hospitality network that exists as an online resource (Couchsurfing.com [4])

\footnotetext{
* Corresponding author: elenaganchuk $@$ gmail.com
} 
similar to a social network that offers its users a search platform (for searching housing, dating, events and travel partners) to meet your recreational and travelling needs at no charge.

So couchsurfing is a new, non-profit hospitality form of tourism that has become increasingly popular in recent years as it allows you to achieve your goals while saving significantly on travel. However, saving money is not a priority.

Couchsurfing is a social phenomenon based on trust, gratitude and willingness to help. The number of people participating in this community is increasing every year. Such a social phenomenon surely could not be ignored by scientists.

Coachsurfing has become the subject of scientific research relatively recently. The beginning of the scientific study of couchesurfing can be considered the work Cosmopolitans on the Couch: Mobile Hospitality and the Internet (2007) [5]. Jennie Germann Molz, exploring mobile hospitality and host-to-guest relationships through the Internet, points out that couchsurfing is not about housing, but rather interpersonal relationships that can be the subject of special research the intersection of online and offline worlds.

Mutual trust as a basis for couchsurfer interaction is emphasized by such researchers as Debra Lauterbach, Hung Truong, Tanuj Shah and Lada Adamic [6].

The scholars from University of Michigan (in Ann Arbor) Devan Rosen, Pascale Roy Lafontaine, Blake Hendrickson [7] offer a concise but at the same time meaningful definition of coaching: CouchSurfing.com is an online cultural exchange community in which members from around the globe coordinate travel accommodations and organize gatherings with fellow members via a social media platform. The authors emphasize that a sense of belonging to the community is the most characteristic of the people often attending local coaching meetings.

Studying the specifics of couchsurfing, it is extremely important to consider the safety of travel and trust in the CouchSurfing.com network, which is noted by scientists, including Clare Toeniskoetter [8].

Vicky Steylaerts and Sean O 'Dubhghaill [9] in their work CouchSurfing and authenticity: Notes towards an understanding of an emerging phenomenon (2012) draw attention to the nature of the phenomenon under study. They consider couchsurfing to be a modern trend, an authentic form of travel, and try to find the boundary between globalization and authenticity, analyzing both the positive and negative individual experiences of couchsurfers.

The Ukrainian couchesurfing researcher Lyubov Bozhko [3] also stresses that the leading idea of couchsurfing is to activate intercultural exchange and socialize in a friendly informal atmosphere. Such communication will allow representatives of different cultures and nationalities to look at problems in a different way and to learn tolerance.

The problematic field of the studied phenomenon is not limited to the aspects discussed above. Detailed research should be carried out on the organizational structure of the virtual hospitality network, the factors influencing its development, classification of types of coaching, identification of regional features of its distribution, which are considered in the article.

\subsection{Research materials}

The information base of the study is statistical and analytical documents: materials from the official site Couchsurfing.org., data from the UN statistics department, as well as reports and statistics from various couchsurfing companies and their branches, publications in magazines, newspapers, Internet networks and other information resources that are freely available.

\section{Results and discussion}

Nowadays the Couchsurfing community is the largest hospitality network and a new type of youth tourism that is rapidly gaining popularity worldwide [10].

The network is positioned as a place of social interaction and an effective means of finding free housing while traveling.

The Couchsurfers community is an institutionalized informal hospitality practice that allows people to socialize anywhere in the world [5].

The Couchsurfing service was founded as a non-profit organization in the US in 2003 by Casey Fenton, who was planning to travel to Iceland. He sent emails to 1500 Icelandic students requesting shelter for an overnight stay because he did not want to stay in an "uninteresting" hotel. Casey received more than 50 positive proposals, which prompted him to seek organizational solutions to this issue.

Couchsurfing International Incorporated was established on April 2, 2003 as a non-profit organization in New Hampshire. On June 13, 2003, the domain name couchsurfing.com was registered. From that moment, the history of the site's creation began.

The site was launched in 2004 in collaboration with Daniel Hoffer, Sebastian Le Tuan and Leonardo Silver. Currently, Patrick Dugan is the general director and financial director of the company. The board of directors includes Casey Fenton and Daniel Hoffer, Sebastian Le Tuan and Leonardo Silver [2, 11].

The network has a rather complex organizational structure and is managed by regional units, which ensure its normal functioning and users smooth travelling. We have developed a schematic representation of its composition (Table 1), which demonstrates that leadership positions are provided by a leadership team that manages four major units, each of which has separate departments and is responsible for performing its functions.

From 2006 to 2011, the development of the website was aimed at creating Couchsurfing collectives - group meetings that lasted several days or weeks and gathered groups of coaches who worked together to improve the site.

Such meetings took place in Montreal, Vienna, Wellington and Quebec. We find such geography of events interesting because it covers coaches from 
different parts of the world once again emphasizing the global nature of this project. Group meetings finished in 2011 as a result of the US federal government banning to use volunteer work in commercial enterprises. The ban also completely stopped funding for the site through donations. Funding is now made through investments from major global corporations and through participants voluntary contributions [11].

Table 1. Organizational chart of the structure of the couchesurfing units.

\begin{tabular}{|c|c|c|}
\hline \multirow{20}{*}{ 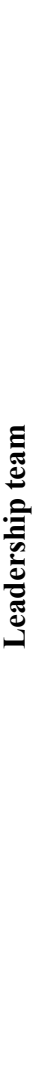 } & \multirow{5}{*}{$\begin{array}{l}\text { Community } \\
\text { operators }\end{array}$} & Chat Coordinators (correspondence) \\
\hline & & $\begin{array}{l}\text { Site member associations } \\
\text { Management }\end{array}$ \\
\hline & & $\begin{array}{l}\text { Ambassadors Management } \\
\text { Department }\end{array}$ \\
\hline & & Membership service (consultation) \\
\hline & & Security department \\
\hline & \multirow{10}{*}{$\begin{array}{c}\text { External Relations } \\
\text { department }\end{array}$} & Software and hardware department \\
\hline & & $\begin{array}{l}\text { Geolocation and Translation } \\
\text { Department }\end{array}$ \\
\hline & & $\begin{array}{l}\text { Department of Innovation and } \\
\text { Development }\end{array}$ \\
\hline & & $\begin{array}{l}\text { Department of Productivity and } \\
\text { Creative Design }\end{array}$ \\
\hline & & $\begin{array}{l}\text { Couchsurfing.com's security policy } \\
\text { department }\end{array}$ \\
\hline & & Media department \\
\hline & & Sponsorship department \\
\hline & & Public Relations Department \\
\hline & & Strategic Marketing Department \\
\hline & & $\begin{array}{l}\text { Couchsurfing Mission Propaganda } \\
\text { Division }\end{array}$ \\
\hline & \multirow{5}{*}{$\begin{array}{c}\text { External } \\
\text { Operations } \\
\text { department }\end{array}$} & Finance department \\
\hline & & Legality Management Division \\
\hline & & Human Resources Department \\
\hline & & Legal Department \\
\hline & & $\begin{array}{l}\text { Couchsurfing Mission and } \\
\text { Achievement Monitoring } \\
\text { department }\end{array}$ \\
\hline
\end{tabular}

In 2011 the company was able to obtain nonprofit status through becoming a part of a nonprofit corporation incorporated in Delaware.

Thus, couchsurfing as a type of youth tourism has a long history of development, and in 15 years of existence has evolved into a network that meets the tourist needs of people, including the youth, and brings together more than 15 million people worldwide. Nowadays, the term "coaching" has become a common name for the entire hospitality exchange movement. Couchsurfing strives for international connections between people and places, creates educational exchanges, raises collective awareness, promotes tolerance and facilitates multicultural understanding. This type of tourism promotes life and outlook change, intercultural experience and exchange that cross oceans, continents and cultures [12].

Couchsurfing's mission is to "create an inspiring experience". The idea is to encourage intercultural exchange via people communication in a friendly informal setting. It enables to realize the natural desire to learn something new, to share knowledge and experience in different spheres of life. Particularly, through such communication people from different countries, representatives of different cultures and nationalities have the opportunity to look at numerous international problems from different perspectives, to learn tolerance [4].

The utilization of Couchsurfing.com resource includes mandatory registration. The users fill in a profile page listing personal information: workplace, training, philosophical views, skills they can teach, favorite music, movies and books, and add their personal photos and photos of their home they offer, if any [13]. The site makes it impossible to change your name and address after registration for the safety of other users.

Coachsurfers can search for hosts using several options: gender, language, age, and location, whom they send messages and agree on further action.

Reliable criteria for choosing the right couchsurfer are:

- positive feedback from both "surfers" and "hosts";

- number of couchsurfing trips made;

- user verification;

- hobbies, vital values that are relevant to each participant individually.

Unreliable indicators in choosing a couchsurfer are:

- lack of detailed personal information;

- several negative reviews;

- the last time of a user site activity;

- the length of a user site registration [13].

Users can publish their travel plans and receive temporary host offers. It is also possible to use a mobile application that allows you to seek asylum in a company with other nearby travelers.

For public communication on the site a forum is divided into groups. The group includes members united by common geographical location, interests, etc.

The features of coaching and network users should include:

- international, global, informal activities;

- intercultural communication;

- non-commercialized exchange of services;

- an authentic form of travel, alternative to tour operators and travel agencies;

- individual activity of the tourist;

- being nature-friendly;

- combination the achievements of globalization with authenticity, by combining online and offline worlds, interacting with local people in their daily lives;

- sheer learning interest as a motive for tourism;

- difference from the traditional type of tourism by motives of travel [11].

Thus, coaching turns from a tourist services searching network into a venue of cross-cultural interaction and human values exchange.

In the course of the research we create a comprehensive classification of types of couchsurfing by several criteria: age of tourists, number of participants, purpose of trip, length of stay, intensity of tourist flow, and direction.

1. By geographical principle, couchsurfing is divided into: 
- local;

- international.

2. According to the age of tourists traveling, coaching is:

- youth (18-30 years);

- adult (30 years old)

- family (mixed age).

3. The purpose of the trip is:

- entertainment;

- event;

- adventure;

- pilgrim-religious purpose;

- nostalgia tourism;

- ecotourism;

- extreme tourism;

- weekend tourism.

4. By the number of participants traveling:

- individual;

- group;

- family coaching.

5. By the duration of the couch's stay with the host:

- short-term (up to 3 days);

- long-term (from 3 to 7 days).

6. By intensity of tourist flow:

- episodic;

- periodic (or permanent).

7. Upon receiving additional services. Within the given classification it is possible to distinguish the following types of coaching:

- House swap is a type of couchsurfing suitable for the adults, since its mandatory criterion is the availability of own housing for people who exchange. The type of accommodation is not important. The most important thing is that your housing requirements and the time of stay coincide with what other tourists are looking for. Sometimes the exchange package also includes a car and food additionally to housing [11].

- Cooksurfing is a type of couchsurfing that aims to share national cuisine recipes with others, simultaneously borrowing other cultures recipes.

- Homestay is a family guest house where you can not only spend the night or eat, but also get acquainted with the lifestyles and habits of the owners.

- Wuffing - a type of couch surfing that allows you to volunteer on eco-farms around the world, to try different agricultural work, to see the peculiarities of farming from the inside, to relieve stress, to practice language, to make friends and take a break from city life.

- Servicing is a type of couchsurfing that includes no more than two nights traveler stay. The main goal is communication and excursion. There are people among the hosts who do not offer accommodation, but are happy to spend time with the tourist, as an interlocutor and a guide.

- Gifting is a kind of couchsurfing, when a tourist makes up for housing by a gift brought from the native land of the tourist. Fridge magnet, a souvenir, a coin, national clothes, music disc, etc. may be presented as gifts. More valuable gift options are also possible.

The success of Couchsurfing social network is due to the facilitation of numerous human interactions worldwide, taking them from the virtual environment into the reality. In order to monitor the operation of the network, site moderators constantly monitor all events that occur there.

Based on the available statistical information [4], we have drawn a number of conclusions.

As of October 2019, 15015978 people are registered on the site. The ratio between the representatives of both genders is given below (Table 2, Fig. 1). In our view, this situation can be explained by the fact that men are less demanding about living conditions, the majority of them seek to experience extreme and are not as safety concerned as women, believing that they can successfully self-protect.

Table 2. Couchsurfing Community Gender Structure (2019) [4].

\begin{tabular}{|c|c|}
\hline Gender & Number of participants, pers. \\
\hline Males & 7463420 \\
\hline Females & 6571456 \\
\hline Others $^{*}$ & 981102 \\
\hline Total & 15015978 \\
\hline
\end{tabular}

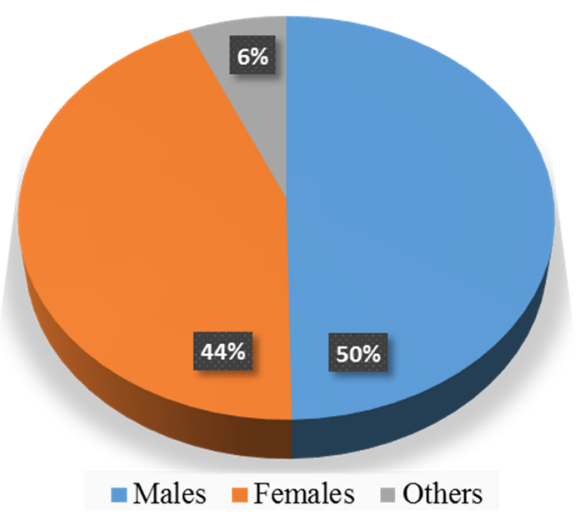

Fig. 1. Diagram of the Sexual Structure of the Couchsurfing Participants* (2019).

*others - are the ones who did not specify a gender when registering at CouchSurfing.com.

You cannot become a couchsurfer until you are 18 years old. This age is the limit on CouchSurfing.org. Active project participants are people from 18 to 79 years. The distribution of project participants by age is presented in Fig. 2.

The average age of coachers is 28 years. The most popular Couchsurfing is among young people aged 18 to $34-37,9 \%$ of the total. People over 50 make up about $2 \%$. This proves that Couchsurfing is a type of tourism mainly for the younger generation.

We also find interesting the educational structure of the members of the couchsurfing community (Table 3, Fig. 3).

The largest share of couchsurfers $(71 \%)$ has higher education (bachelor and master degrees). The number of persons having high education is significant ( $24 \%)$. If we consider couchsurfing to be a kind of cognitive tourism, it becomes clear the aspiration of people with higher education to get to know the outer world, to get acquainted 
with new places and cultures, their need for communication with representatives of other social communities.

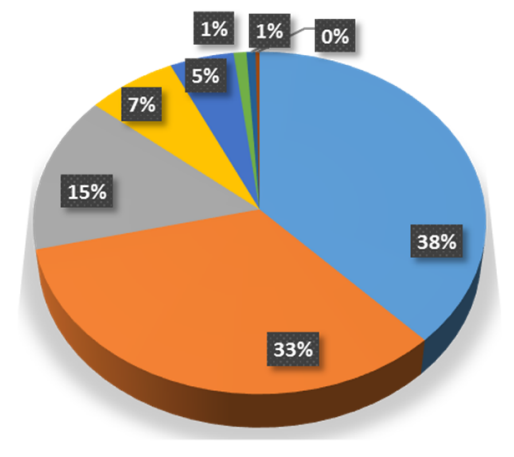

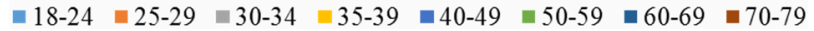

Fig. 2. Graph of Age structure of the couchsurfing community (2018) [4].

Table 3. The Couchsurfing Community Educational Structure (2019) [4].

\begin{tabular}{|c|c|}
\hline Education & $\begin{array}{c}\text { Number of participants, } \\
\text { pers. }\end{array}$ \\
\hline High education & 3663835 \\
\hline Bachelor degree & 8829267 \\
\hline Master degree & 1822077 \\
\hline $\begin{array}{c}\text { Post-graduate/ doctoral } \\
\text { degree }\end{array}$ & 140160 \\
\hline Other & 560639 \\
\hline Total & 15015978 \\
\hline
\end{tabular}

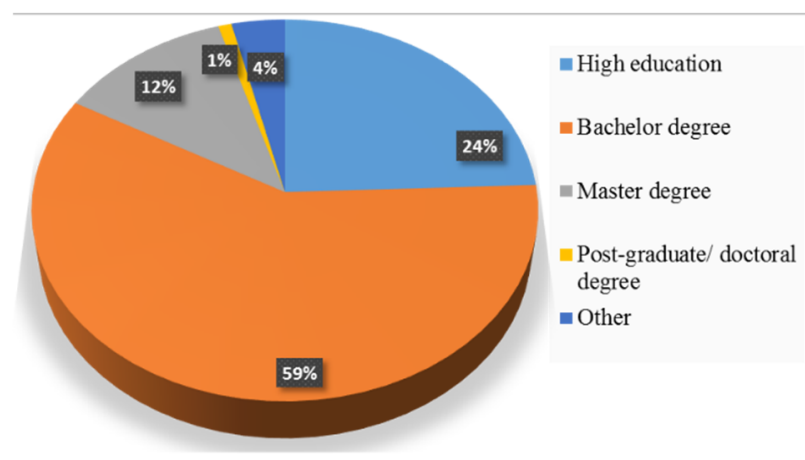

Fig. 3. Diagram of the Educational Structure of Couchsurfing Community (2019).

Couchsurfing is not only about hospitality but also about socializing, meeting new people and making new connections around the world. Therefore, the profiles of participants also provide information on what kind of services a particular coachsurfer can provide (Table 4). Hosts offering accommodation only make up 30,3\%, and the ones additionally offering excursions and walks are $16,8 \%$ and $15,6 \%$. This reiterates the desire of the community members not only to provide (get) a place to spend a night, but also to learn something new, to make new friends, to show trevellers around the city, its architecture, history, and culture.

$12,1 \%$ of hosts with no conditions for long-term tourists can offer a temporary stay without accommodation. They are happy to meet couchsurfers for a cup of coffee, to give a city tour, and make them feel at home. However, most of the Couchsurfing participants are still able to accommodate tourists for the night.

Table 4. Type of hosting services (2019) [4].

\begin{tabular}{|l|c|}
\hline \multicolumn{1}{|c|}{ Service } & Number of participants, pers. \\
\hline Overnight stay & 4544953 \\
\hline Coffee or other beverages & 3783515 \\
\hline Excursion & 2522876 \\
\hline Walk & 2342556 \\
\hline Temporary overnight stay & 1822078 \\
\hline Total & 15015978 \\
\hline
\end{tabular}

We reckon the following factors contributed to the development of couchsurfing:

- globalization of the world economy, open borders;

- transportation development,

- the Internet, its rapid development and the social networks influence in society;

- the overall community well-being, that encourages travelling;

- democratization of society and liberalization of interpersonal relations, that stimulate people (especially youth) to refuse a planned package tour, map up an independent route of their own travel, international peers communication;

- change in the nature of tourism and tourists behavior, new forms of tourism and ways of travel.

Analyzing the statistics of the number of couchsurfers in the world for 2019 [4], we can distinguish the following groups of countries:

- With high number of participants (> 500000 people) Canada, USA, Germany, France, Great Britain.

- With enough (100 - 500000 people) - Spain, Italy, Brazil, China, Australia, Ukraine and others.

- With an average number (20 - 100000 people) - Peru, Republic of South Africa, New Zealand, Ireland, Tunisia and others.

- Low numbers $(<20,000$ people $)$ - Bolivia, Panama, Mongolia, Iran, Estonia, Chad and others.

Couchsurfers have access to the most visited countries, the number of participants and the relationships between them, which is provided on the site [3, 10, 12]. Regarding the regional features of couchsurfing, the most popular regions include (Fig. 4).

Europe. Overall, there are the largest number of Couchsurfers in the European region. Inhabitants of this part of the world were the second after Anglo-America involved in coaching. But at present, Europe has a leading position in the number of countries with more than 200,000 couchsurfers (UK, Germany, France).

Modern tourism in this region is mainly cultural and historical and generally tours the Western sub-region. The Old World is the most tourist-friendly part of the world. European countries are very conveniently located to one another: common borders and a developed network of transport routes. EU countries are characterized by visafree travel, that is why tourism in Europe is focused not only on foreign visitors from other continents, but also on its neighbors. 


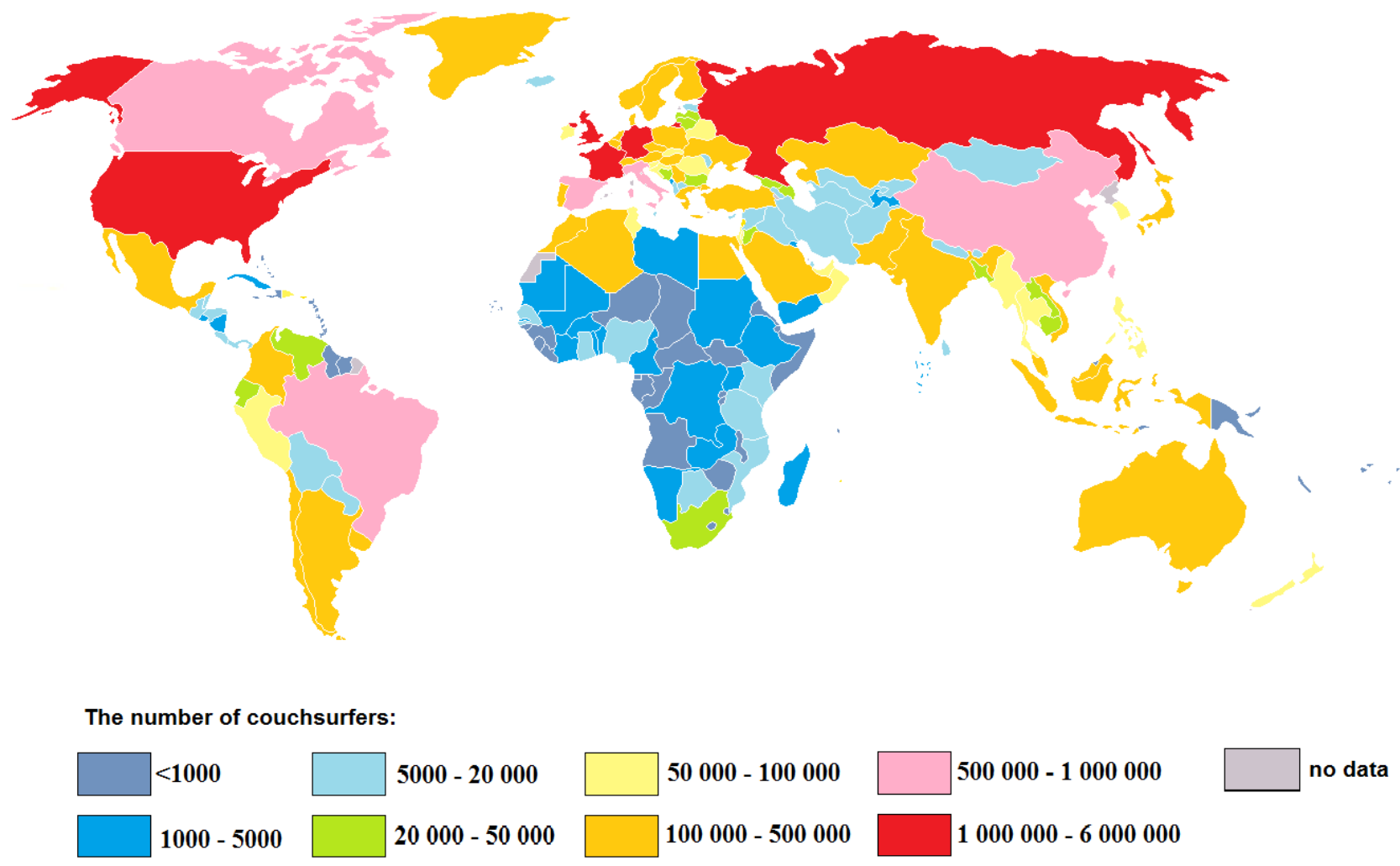

Fig. 4. Map "Number of Couchsurfers by Country $(2019)$ " [4, 11].

Hosts in Europe offer comfortable accomodation, so family and adult coaching is also widely represented alongside with youth coaching [14].

The top couchsurfing destinations are the most famous tourist cities: Paris, London, Berlin, Vienna are in the top ranking.

The popularity of the European region among couchsurfers is due to: favorable geographical location; high level of socio-economic development; political stability; common currency; different types of tourism combination (cognitive, wellness, mountain-skiing and others); accomulation of tourist sites; education, kindness, openness of the hosts, and their willingness to provide everything necessary for a quality rest of their guests.

This type of recreation among the world's population is constantly urged in modern conditions.

Anglo-America. Anglo-American Region is the birthplace of couchsurfing. This is where this network came into being and rapidly developed. In terms of number of visits from abroad, it is inferior to the European region, but the number of local travels is very high there. The number of coachsurfers in Canada and the United States is 3 million [15].

Coaches visit these countries to admire the wonders of nature, vast cities, places of interest, filming of wellknown films and TV shows, entertainment venues, long beaches, and to meet the indigenous people of these areas, to see their lifestyle. American hosts are mostly open, friendly, adventurous and active youth, seeking new acquaintances and intercultural exchanges, but offering predominantly modest overnight accommodations.

Coaches choose this region because of: the large number of Internet and Coachingsurfing site users; plenty of natural and anthropogenic sites and other places to visit; specific national charater of the Americans; high level of services, transportation and communication; a large number of youth events, festivals, concerts, parades, etc.; democracy and openness of society, government and law.

Couchsurfing leaders in the Anglo-American region are: New York City, Chicago, Washington, Montreal, Quebec, San Francisco, Los Angeles, Boston, and the others.

Australia and New Zealand. Despite the geographical isolation of these countries from the centers of coaching, more than 500 thousand people form this region participate in it.

The countries of the region are highly economically developed as well as the Western European countries. The development of tourism is facilitated by: a large number of natural and geographical advantages because of which couches come here (ideal beaches, sandy dunes, endemic organic world, Great Barrier Reef, etc.); urban landscapes, water parks, galleries, museums and festivals [16].

Coachsurfing has achieved the greatest development in cities such as Sydney, Wellington, Adelaide, Brisbane, Melbourne, Auckland, Christchurch.

So, couches travel to Australia and New Zealand because of the uniqueness and strangeness that hosts are happy to offer.

Thus, the popularity of couchsurfing in the abovementioned regions (Europe, Anglo-American, Australia and New Zealand) is explained by the following general features: global distribution and the large number of Internet users; the desire to develop alternative types of tourism in order to gain new experiences, acquaintances, visit new places; high availability of recreational 
facilities; mentality (credibility, friendliness, openness, etc.); free of charge services: accommodation, tours, communication, etc.

The average development of couchsurfing is in the following regions: Asia (leading countries in the number of couchsurfers are China (750 000), India (400 000)) and Latin America (the leading countries in the number of couchsurfers are Brazil (700 000 pers.), Mexico (400 000), Argentina (400 000) [4].

The countries of these regions have large territories and dramatically vary in the development.

Tourism is becoming an increasingly important item of income for these countries. Couchsurfers choose this region because it has: historical and architectural monuments; natural wonders, large in area and variety of flora and fauna of the nature reservations; picturesque metropolises; original traditions with a millennial history; specific reginal cuisine.

The main problem that hinders the active spread of couchsurfing in these countries is the huge disparity between couches and hosts, because not all couchsurfers are willing to have travelers for free. The reasons are very diverse - from worries about the hosts and their property safety, to psychological traits that cause anxiety and distrust in potential hosts to this type of journey. Political instability, national-ethnic conflicts, and infectious diseases should be attributed to the problems of the development of coaching in Asia and Latin America.

Thus, these regions have enormous potential for the couchsurfing development, but the locals reluctance or inability to receive couches prevent the spread of this type of tourism there.

Africa, the Middle East, Central America and Oceania are the least developed areas for couchsurfing. The reasons for this are: low socio-economic development of the countries of these regions; unstable political situation; lack or poor development of tourism infrastructure; the spread of dangerous diseases; unsanitary and other [11].

In Africa, there are generally up to several million couchsurfers in countries such as the Republic of South Africa, Egypt, Morocco, Tunis, Algeria and several other countries.

In Oceania, only one country New Caledonia have up to 500 couchsurfers, in other countries there are up to several dozen users.

In these regions, couches are attracted to virgin landscapes, the unique culture of the people who inhabit these territories. There is a tendency to increase the number of hosts.

Besides the positive aspects of tourism growth in general and couchsurfing in particular, which are described in the article above, there are also significant risks caused by worsening sociocultural, economic and environmental conditions of world destinations.

So, A. Seselkin [17] claims that tourism activities can directly or indirectly affect the environment; contribute to the depletion of natural resources, intolerant attitude to the culture of the visited country; violation of human rights related to the tourism sector; contribute to higher prices and economic instability, etc.

Meanwhile, tourism is one of the most promising growth stimulus for the global economy and, with appropriate investments, it can continue to grow steadily, contributing to the necessary economic growth, employment and development.

Couchsurfing as a global hospitality network and a kind of sustainable youth tourism is bound to reach such goals of sustainable development (SDGs) [18]:

- good health and prosperity (SDG No. 3;)

- sustainable economic growth, full and productive employment (SDG No. 8);

- reduction of inequality (SDG No. 10);

- rational consumption and production models (SDG No. 12), etc.

However, the contribution of tourism and couchsurfing is not limited to these goals, as it can directly or indirectly contribute to the achievement of all other Sustainable Development Goals [17].

\section{Conclusion}

1. Consequently, coaching is a kind of youth tourism with its specific features that make it different from other types of tourism (non-commercial, international, informal activities, free exchange of services, differences in travel motives, etc.), as well as characteristics that are common to many types of tourism (intercultural exchange through communication with people from all over the world, personal activity of tourists, deep interest in learning, the desire for recreation, etc.).

2. Moreover, the phenomenon of couchsurfing can be classified into the standard categories (age and gender of tourists, number of travelers, duration of travel, etc.), as well as special branches of the network (gifting, wuffing, homestay, etc.).

3. The development of couchsurfing in different countries has its own peculiarities: more developed countries attract many millions of tourists due to many appealing factors, in developing countries the number of tourists is less because of certain problems of various nature, but the fact that Couchsurfing annually attracts more and more followers is undeniable.

4. This study is open-ended and may continue to explore the historical and regional changes in the phenomenon of couchsurfing. In addition, the theoretical interest is primarily raised by the issues of economic and social models of exchange relations that underlie couchsurfing, the impact of market relations [2]. The practical problem is to determine how hospitality changes under the influence of innovative technologies, as well as to formulate a number of useful tips for beginners and experienced coaches.

5. We agree with A. Sesyolkin [17] and believe that the tourism sector can contribute to the achievement of sustainable development goals. At the same time, it is necessary to minimize tourism harmful impact on the environment and cultural heritage including.

\section{References}

1. Resolution adopted by the General Assembly on 25 September 2015, Transforming our world: the 2030 Agenda for Sustainable Development (2015), 
https://www.un.org/ga/search/view_doc.asp?symbol $=\mathrm{A} / \mathrm{RES} / 70 / 1 \&$ Lang=E. Accessed 20 Dec 2019

2. S. Nekludova, V. Kabrin, Formirovanie novogo tipa mobil'nogo obraza zhizni lichnosti V transkul'tural'noj kommunikacii (Formation of a new type of mobile personality lifestyle in transcultural communication). Sib. J. of Psych. 65, 66-82 (2017). doi: $10.17223 / 17267080 / 65 / 5$

3. L.D. Bozhko, NAMSCAH 2, 8-13 (2016)

4. Couchsurfing International, Meet and Stay with Locals All Over the World (2020), https://couchsurfing.com. Accessed 31 Mar 2020

5. J.G. Molz, in Mobilizing hospitality. The Ethics of Social Relations in a Mobile World, ed. by J.G. Molz, S. Gibson (Routledge, London New York, 2016), p. 65

6. D. Lauterbach, H. Truong, T. Shah, L. Adamic, Surfing a Web of Trust: Reputation and Reciprocity on CouchSurfing.com. Paper presented at the 12th IEEE International Conference on Computational Science and Engineering, CSE 2009, Vancouver, BC, Canada, 29-31 August 2009. doi:10.1109/CSE.2009.345

7. D. Rosen, P. Lafontaine, B. Hendrickson, J. N Med. Soc. 13(3), 1-18 (2011)

8. C. Toeniskoetter, Honors thesis, University of Michigan - Ann Arbor, 2013

9. V. Steylaerts, S. Dubhghaill, CouchSurfing and authenticity: Notes towards an understanding of an emerging phenomenon. J. Hosp. Soc. 1(3), 261-278 (2012). doi:10.1386/hosp.1.3.261_1

10. L. Gilmutdinova, J. NM, 9(51), 52-53 (2013)

11. T. Lohvynenko, Master's thesis, Kryvyi Rih State Pedagogical University, 2018

12. D.-J. Chen, Couchsurfing: Performing the travel style through hospitality exchange. Tourist Studies 18(1), 105-122 (2018). doi:10.1177/1468797617710597

13. E. Dacko, Couchsurfing: vdohnovlyayuschiy opyit (Couchsurfing: an inspiring experience). (2015), http://niklenburg.com/couchsurfing/. Accessed 20 Nov 2019

14. J.-E Tan, The leap of faith from online to offline: An exploratory study of Couchsurfing.org. Paper presented at the Trust and Trustworthy Computing, Third International Conference, TRUST 2010, Berlin, Germany, 21-23 June, 2010

15. S. Nordin, Tourism of Tomorrow - Travel Trends and Forecast of Change (Utredningsserien, ETOUR, 2005), p. 98

16. A. Glazunov. Kauchserfing (CouchSurfing) - chto eto takoe i kak im pol'zovat'sya ili samye chasto zadavaemye voprosy (CouchSurfing - what is it and how to use it or the most frequently asked questions) (2019), https://www.life-in-travels.ru/couchsurfing/. Accessed 20 Nov 2019
17. A. Sesyolkin, Sustainable tourism as a priority in sustainable development strategies, J. Bridg. ICTSD, 10(4), 4-8 (2017)

18. 17 Goals to Transform Our World (2019), https://www.un.org/sustainabledevelopment/. Accessed 25 Dec 2019 